\title{
Editorial
}

\section{Género, participación ciudadana y poder: una relación problemática}

Para una importante corriente de pensamiento de la actualidad, la participación ciudadana es el elemento que debe fortalecerse si se quiere que exista democracia real. Pero, ¿hasta que punto el discurso de la participación ciudada$n a$ incide efectivamente en el problema de la dominación de género?

Nuestras sociedades latinoamericanas, posdictatoriales, se precian de ser democráticas por cuanto en ellas se puede discutir abiertamente sobre casi cualquier cosa. Lo que durante los regímenes militares estaba proscrito a sangre y fuego, ahora se trata con soltura. Es más, dirian algunos: en nuestras democracias hay participación ciudadana en tanto la sociedad civil debate, discute sobre temas que antes eran el coto privado de las élites poderosas. Asi, observamos foros, mesas de discusión, debates ciudadanos, cabildos abiertos, consultas, hasta el referéndum, etc. Los temas vinculados con los problemas de género -marginación, violencia en todas sus expresiones, restricción del acceso a cuotas de poder, por mencionar algunos- son objeto de esos instrumentos de participación ciudadana. Actualmente, en nuestras sociedades se habla abierta- 
mente sobre violencia sexual, sobre los distintos modos que toma el acoso, sobre salud reproductiva, sobre sexualidad. No menospreciamos los avances que se han dado en lo que respecta a los derechos de las mujeres. Sin embargo, en nuestras sociedades en las que, más que nunca, se discute sobre el problema de género, ¿por qué las diversas formas de opresión continúan vigentes? ¿Por qué, cuando existe apertura y posibilidad de discutir y de participar sobre temas de importancia, un conservadurismo de nuevo cuño parece ser el que toma al fin las decisiones que afectan temas importantes, como la salud reproductiva, el aborto, la participación de las mujeres en el ámbito público?

Alguien puede decir que no es fácil erradicar las formas de opresión por género, ya que están afincadas en nuestras culturas desde hace siglos. Esto es cierto. El problema reside en ver hasta qué punto el discurso de la participación ciudadana no oculta, a pesar suyo, esas formas de opresión. En nuestras sociedades, la participación ciudadana se vería encarnada en la apertura de debates sobre variados temas. Quizá las palabras de la periodista mejicana Sara Lovera nos puedan aclarar al respecto. En uno de sus trabajos acerca de los medios de comunicación —que publicamos en esta entrega-, menciona el tema de la regulación de los contenidos: "Algunos diarios han creado comités ciudadanos, y se están discutiendo códigos de ética, pero estas discusiones no se están abriendo a la sociedad y de ellas, las mujeres estamos ausentes".

Quizá ahí resida el problema. El discurso de la participación ciudadana puede revertirse de manera perversa y servir para ocultar una situación opresiva. Hay debate en nuestras sociedades, sí, y qué bueno que lo haya. Pero en ese debate -que se pretende amplio, pues concita a personas de distintos enfoques políticos - no participan todas y todos. La pretendida apertura sólo abarca a quienes tradicionalmente se les ha asignado autoridad para decidir sobre temas de interés público: la clase política. Esa expresión, clase politica, no obedece a una mera sutileza lingüística. Revela la existencia de un estamento social que tiene acceso al poder de la esfera pública, y es el que está autorizado a opinar, a debatir y, lo que es más importante, a decidir, a definir el rumbo de la "publicidad". Quedan afuera, como siempre, las mujeres y los grupos sociales a los que no se les ha reconocido poder de decisión sobre estos asuntos. $\mathrm{O}$ bien, en el mejor de los casos, estos sectores podrian estar incluidos en esos mecanismos de participación ciudadana. Sin embargo, estos últimos quedan relegados a una función, digámoslo asi, de espectáculo: ofrecen el coro de opiniones plurales de una sociedad democrática, pero no tienen, muchas veces, peso como para incidir en las decisiones que afectan a la vida pública. Sin embargo, hay que repetirlo hasta la saciedad: no quiere decir que el debate ciudadano sea algo estéril, pues hay ocasiones en que ha servido para obrar cambios importantes en el ámbito público. Lo que estamos señalando son sus limitaciones, en contextos donde el acceso al poder que incide en la "publicidad" no abarca a todo el mundo. 
La mera inclusión de las mujeres en el debate - no sólo sobre los problemas de género, sino también sobre las decisiones que afectan a la sociedad - tampoco es suficiente. Porque se puede dar un espejismo de participación ciudadana, ofreciendo instrumentos en los que la ciudadanía puede expresar sus opiniones, pero también se puede mantener el poder alejado de esos ciudadanos y ciudadanas. Las maneras autoritarias, patriarcales, verticalistas y excluyentes de ejercer el poder pueden pervivir y hasta se legitiman, valiéndose de estos instrumentos y de estos discursos. Los sistemas opresivos tienen una capacidad de mimetismo verdaderamente pasmosa. No es de extrañarse de que los que han ejercido tradicionalmente el poder hayan reciclado su lenguaje y hasta tengan mucho cuidado para aparentar que su discurso tiene enfoque de género. Tampoco deberia sorprender que esos grupos dominantes introducen en su discurso elementos tales como los de participación ciudadana, consenso, dinámicas participativas.

Una de las falacias de uso corriente en nuestras sociedades es que el poder es solamente político y que éste se puede ejercer únicamente desde el aparato estatal. Gracias a esa falacia, las mujeres - y los grupos tradicionalmente subalternos - se han visto marginadas del ejercicio del poder. Poder es precisamente lo que la palabra dice: poder decidir sobre los temas que nos afectan; poder apropiarse de los medios para tener una vida más plena. $\mathrm{Y}$ no es que caigamos en la ingenuidad y digamos que el poder estatal, el poder político, tal como se concibe tradicionalmente, no tenga importancia: lo que queremos afirmar es que reducir el poder a estas dimensiones facilita que aquellos sectores que no tienen acceso a la toma de decisiones en el Estado opten por la pasividad.

La lucha por erradicar la opresión de género puede y debe entablarse en los espacios de participación ciudadana, pero ello debe hacerse críticamente. Poder debatir sobre los problemas que expresan la dominación genérica es importante, pero más importante es que se ataquen las causas de esta dominación. Los sistemas democráticos tienen una paradoja inherente: un grupo "privado" - la clase política, expresión suma, no sólo de la dominación de clase, sino también de la dominación patriarcal, por mucho que haya mujeres ejerciendo cargos de gobierno, o que en ciertos gabinetes figuren personas "de izquierda"- es el que tiene poder para decidir sobre asuntos "públicos", en nombre de los grupos sobre los cuales ejerce, precisamente, ese poder. El desmontaje de las formas de opresión de género es posible aprovechando los instrumentos de participación ciudadana, con todo y sus limitaciones, pero, a la vez, creando nuevos instrumentos, nuevos métodos en los que las mujeres y los grupos a los que se les ha vedado el poder público puedan apropiarse de nuevas posibilidades de realización y de autodeterminación. 